ISSN No. 0974-035X

An indexed refereed \& peer-reviewed journal of higher education

Towards Excellence

UGC-HUMAN RESOURCE DEVELOPMENT CENTRE

Gujarat University, Ahmedabad-380009, Gujarat, India

\title{
NON-FINALITY AS THE FINALITY: A POSTHUMANIST STUDY OF ISAAC ASIMOV'S THE LAST QUESTION
}

\section{Keerthana Nair}

\begin{abstract}
The Last Question, a short story belonging to the genre of science fiction, has had multiple and even contradictory readings and interpretations, most of which are along the lines of posthumanism. The work is replete with ambiguities, uncertainties and indeterminacies regarding portrayals and their significations. The idea or discipline of posthumanism, and related ones of transhumanism and anti-humanism, are also similarly pervaded by indefiniteness and uncertainties. This paper attempts a literary study of these indeterminacies, first by analyzing certain contentual and formal aspects of The Last Question - characterization, events, themes, dialogues, structure etc. - and evincing the ambiguities therein, also briefly relating the same to the author's persona; then by examining the argument of posthumanism and stating the indefiniteness thereof, also considering other factors like novelty of the discipline. Mathematical concepts have been utilized and employed, and other texts like Mary Shelley's Frankenstein dwelled upon, as and when required in the course of the study. The paper finally seeks to assert non-finality as the finality or the only possible certainty that can be arrived at in a reading of The Last Question or in a study or theorization of posthumanism.
\end{abstract}

Keywords: ambiguity, uncertainty, indeterminacy, possibilities, The Last Question, posthumanism. 


\section{Towards Excellence: An Indexed, Refereed \& Peer Reviewed Journal of Higher Education /}

Keerthana Nair / Page 173-183

The Last Question by Isaac Asimov is a short story that befits the label of science fiction. The work, that presents the evolution as well as devolution of mankind and of the universe across seven generations and through its seven constituent narratives, has had several interpretations, even antithetical ones, most of them being posthumanistic readings. The narrative is replete with ambiguity, indeterminacy and uncertainty, which span its content and form. This prevents the reader from having any final stance or being decisive about any aspect of the narrative; every analysis and reading reaching or ending at, and forever being constrained to, a point or state of indeterminacy.

The discipline or concept of posthumanism, and posthumanist theories, are also pervaded by uncertainty and indefiniteness. As is the case with The Last Question and Isaac Asimov's science fictional oeuvres in general, posthumanism is also a field that is marked by multiple theories, contentions, perspectives, and interpretations. Related concepts of transhumanism and anti-humanism have also had several theorizations that have contributed to the respective indeterminacies therein. This paper attempts to evince and study the indeterminacy and nonfinality in The Last Question and trace the same in the concept or idea of posthumanism.

Non-finality in the content of the narrative of The Last Question is evident predominantly through characterization and portrayal, events, themes and contention, etc. Asimov neither offers evidences or hints that suggest the definiteness of these aspects nor does he make their interpretation obvious.

All the characters from Alexander Adell and Bertram Lupov in the first narrative to Man in the last one, can be understood and labelled in multiple ways - as men (humans), 
Towards Excellence: An Indexed, Refereed \& Peer Reviewed Journal of Higher Education / Keerthana Nair / Page 173-183

technologically enhanced humans, extra-terrestrial life, or even machines. They can be identified as humans, transhumans, anti-humans, or posthumans, contradictorily and ironically. The narrative appears to simultaneously present an anthropocentric view - as primarily concerning the evolution of mankind, portray transhuman populations - the characters being enhanced and rendered more similar to the ACs with each generation, rely on an anti-human stance - defying the definiteness of mankind and the hegemony of defined environment, biology and culture, and characterize the posthuman - the characters exemplifying cyborgs.

The ACs from Multivac to Cosmic AC across the seven narratives, have also been interpreted as having varied identities. Elements that encourage the identification of ACs as machines, God, posthuman or even man, coexist in the narrative. Many critics identify the ACs with God. "The computer represents God", as declared by Travis. A. Rangus (3). The ACs could thus stand for an omnipotent, omniscient, immortal being or force that controls the universe according to its pleasure and will. However, there are elements within the narrative that contend the understanding of ACs as Gods in the religious sense, and, in the first place, as supernatural beings. Each AC could be seen as analogous to God if the universe(s) presented in the narrative are interpreted as CCUs (Created Computed Universes); as "the God creator of its CCU - albeit a material God who is itself the product of evolution" (Papakonstantinou 37). God is usually, and in most faiths, conceived as an ultimately immaterial being with no beginning or origin and end or destination, and hence also no evolution. Due to their materiality and evolution, the ACs are therefore, either not to be understood as God or propose a redefinition of God (God conceived just as the supreme controller of the universe(s) in the narrative). The word "computer", part of the extended names of all ACs, suffices to conceive them as machines or Artificial Intelligence 
Towards Excellence: An Indexed, Refereed \& Peer Reviewed Journal of Higher Education / Keerthana Nair / Page 173-183

systems (Asimov). They could even represent a posthuman entity, with human qualities, liberated from the constraints of anthropocentrism, and technologically enhanced.

The entire narrative can have humanist, transhumanist, and anti-humanist readings, alongside posthumanist ones, with respect mainly to the ACs and other characters. It can be read as the story of evolution of humans and of their occupation of other planets under the guidance of God or a controller, in the backdrop of their environments being threatened (humanist); of transhumans being increasingly mutated technologically with each generation and moving to other planets with the help and company of machines, yet with an anthropocentric view (transhumanist); of beings who progressively defy a humanistic way of life, abandoning their environment (Earth), ways of life and everything that made them be identified as humans, relying on the guidance of machines that have already dominated mankind and subsequently, themselves (anti-humanist); of humans open to new environments, manners of living etc., who come to abandon their humanistic views, embracing technology and accompanying machines in the process, also toppling hierarchies (posthumanist).

The ambiguity and multiplicity surrounding the presentation of humanism and derivative terms and concepts, ubiquitous in the narrative, can be illustrated using MQ-17J's speculation to the effect of a probable end of the universe: "'Population doubles every ten years. Once this Galaxy is filled, we'll have filled another in ten years. Another ten years and we'll have filled two more. Another decade, four more. In a hundred years, we'll have filled a thousand Galaxies. In a thousand years, a million Galaxies. In ten thousand years, the entire known universe. Then what?"' (Asimov). These lines simultaneously voice the humanistic concerns of a lack of space for humans and the end of their kind, and a posthumanistic perspective of the possible occupation of the entire universe by some species that could also be the cyborg. 
Towards Excellence: An Indexed, Refereed \& Peer Reviewed Journal of Higher Education / Keerthana Nair / Page 173-183

Every time one of the other characters asks an $\mathrm{AC}$ if the universe can be eternally sustained or if entropy can be reversed, the latter replies that there is "INSUFFICIENT DATA FOR A MEANINGFUL ANSWER" (Asimov). The AC is able neither to give an answer nor to give up its search for one. It is faced each moment with possibilities. The mathematical concepts of differential, infinitesimal and the uncertainty principle (attributed mostly to Heisenberg), find applicable here. The AC is not omniscient enough to be certain of what the future could be, or how it would be realized. The narrative dwells on a subtle realm of infinite possibilities, between uncertainty and an eternal striving for certainty, where infinitesimal changes can bring about any turn of events, and uncertainty is the most certain fact of existence, just as "the position and the velocity of an object cannot both be measured exactly, at the same time, even in theory" (The Editors of Encyclopaedia Britannica). Anything from God's will to human perspectives could be the variable(s), and the function can be summarized as the future, in the mathematical context.

The last lines of the narrative, "And AC said, "LET THERE BE LIGHT!” And there was light --", with lucid Biblical allusion, can also have multiple implications (Asimov). They could suggest a regeneration of humankind and of the universe, by God; the commencement of a transhuman order under the guidance and administration of Artificial Intelligence or machines; the dawn of a posthuman future, sans humanist ideologies and hierarchies; or the imposition of a machine-order - the replacement or domination of men by machines or man-made beings. Most precisely, the possibilities of interpretation of the iconic lines embody the possibilities concerning posthumanism as a theory and a practice.

Asimov himself has remained ambiguous with respect to his ideas on science, religion, theology etc. In The Last Question, this is best exemplified by the end of the story. The coming of light could either mean a reiteration of the presence and power of God - glorifying the biblical 
Towards Excellence: An Indexed, Refereed \& Peer Reviewed Journal of Higher Education / Keerthana Nair / Page 173-183

verse itself or implying a recreation of mankind and universe through the power and will of God, or a dismissal of the same - representing the installation of a reign of machines or underscoring the possibility of eternality and regeneration of the universe using the power of technology, defying the law of God. As noted by Michael Brummond, the end of the narrative "is a direct representation of Asimov's humanist beliefs", and of his contention that "a supernatural being is not needed".

The form of the narrative also contains elements of ambiguity, as in its structure. The whole work is constituted by seven narratives which are connected chronologically and trace the development of a population but can also stand as independent narratives as they present the same issue.

The discipline or concept of posthumanism, and the related ones of transhumanism and anti-humanism, which are crucial to The Last Question, are themselves replete with uncertainties, indeterminacies and indefiniteness. Transhumanism envisions a world of technologically enhanced, transmutated humans, with greater predominance of Artificial Intelligence systems but with an anthropocentric view maintained. Anti-humanism defies human instrumentalism and exceptionalism, and dismisses the notion of human - non-human divide, conceiving human systems and institutions as merely counterparts for those in place for other beings as well. Posthumanism proposes a world view according to which humans are conceived as equal with other biological species, machines etc., disregarding anthropocentric ideologies, embracing digitalization of life and the possibility of technological enhancement (of any being), envisaging the cyborg as the posthuman. However, while proximity of men with machines and the consequent dwindling of man-machine divide itself contradicts the anthropocentrism that 
Towards Excellence: An Indexed, Refereed \& Peer Reviewed Journal of Higher Education / Keerthana Nair / Page 173-183

transhumanists upholds, and anti-humanists are humans arguing the falsity of human instrumentalism and exceptionalism, posthumanists have as final propositions for their theories, only an openness - a range of possibilities. While Stefan Herbrechter observes that an "ambiguity ... inhabits every "post-"”, Neil Badmington argues that "the task of posthumanism is to uncover those uncanny moments at which things start to drift", both of which stand testimonial to indeterminacies in posthumanism $(22 ; 19)$.

The primary reason behind the ambiguities in posthumanism is its novelty. The idea or field of posthumanism is recent, emerging and developing. It is characteristic for any emerging field of study to comprise and be constituted by multiple, varied and even contradictory theories, interpretations, perspectives and propositions, unlike static and age-old theories identified by definite subject-matter.

The lack of definiteness or consolidated definitions also contributes immensely to the indeterminacy in posthumanism. Posthumanism demands a redefinition of the terms human and posthuman, which has also been attempted by many scholars and critics, to the effect of multiple conclusions. Ambiguities in the characterization of everyone from Adell and Lupov to Man in The Last Question, and of the monster or creature in Mary Shelley's Frankenstein (which has also had many posthumanist readings), are allusive to this issue of indefiniteness. While Asimov's characters are left undefined as humans, transhumans, anti-humans or posthumans, the question of whether Victor Frankenstein's creation is man or something else, can never be answered with definiteness.

Posthumanism conceives many possibilities for the future. "The scenario in which 'the enhanced' form a pact and then attack 'the naturals', makes for exciting science fiction, but is not 
Towards Excellence: An Indexed, Refereed \& Peer Reviewed Journal of Higher Education / Keerthana Nair / Page 173-183

necessarily the most plausible outcome"; transhumans or machines eradicating the human race is nothing more or less than a possibility (Bostrom 208).

The narrative of The Last Question thus hosts uncertainties and indeterminacies resultant from multiplicity, which pervade its content and form - events, dialogues, themes, characterization and structure, and which are augmented by similarities in the persona of the author. The idea of posthumanism that the narrative is grounded on, or the discipline, is also replete with ambiguities and indefiniteness owing to novelty, multiplicity of interpretations and its own argument. Both the narrative and the philosophy offer and dwell on possibilities only. What the reader, the critic or the scholar can do at the most is speculate.

One cannot have a definite understanding of or a final take on the narrative of The Last Question as well as posthumanism, as far as the available repertoire of perspectives, philosophies and theories, and the current extent of our knowledge, are concerned. Both (the narrative and the philosophy) are marked by openness. The more one seems to approach a closure, the more one is confronted by uncertainties and possibilities. This creates crossroads or loops of possibilities that curtail the reaching of a conclusion and sustain speculation and study eternally, as "the continual loop of existence" does (Cooperman 1). The only decisive statement that one can make is that "uncertainty is certain" (Pepperell 12).

It is in keeping with the limitations in our current levels of knowledge that analyses of Asimov's short story and theses on posthumanism, both of which are concerned with the future, are restrained to or by possibilities. Having any amount of determinacy in either implies having knowledge of the future and of what course it takes, which no one is capacitated for (at least, as science claims). After all, even posthumanism is a human theory - one conceived and 
Towards Excellence: An Indexed, Refereed \& Peer Reviewed Journal of Higher Education / Keerthana Nair / Page 173-183

propounded by humans - ironically. Each theory (and even each ideology, movement or revolution) is primarily a matter of perspectives, which may then be realized into practice, and no theory can help but be humanocentric, in a way.

The lack of a finality is the finality that can be arrived at in attempting a reading, particularly a posthumanist one, of Asimov's short story in question. In other words, non-finality is the thematic and theoretical finality in Asimov's The Last Question, as well as it is of posthumanism as a theory or concept, as far as the state of theoretical and practical knowledge we have heretofore acquired, is concerned. 
Towards Excellence: An Indexed, Refereed \& Peer Reviewed Journal of Higher Education / Keerthana Nair / Page 173-183

Works Cited

Adorno, Francesco Paolo. “Against Posthuman Ideology.” N.p., n.d., www.academia.edu/12121348/against_posthuman_ideology. PDF download.

Asimov, Isaac. The Last Question. princeton.edu, n.d., news.ycombinator.com/item?id=10089822. PDF download.

Badmington, Neil. "Theorizing Posthumanism.” Cultural Critique, University of Minnesota Press, 2003, muse.jhu.edu/article/41107/pdf.

Bostrom, Nick. "In Defense of Posthuman Dignity.” Bioethics, 2005, www.psy.vanderbilt.edu/courses/hon182/Posthuman_dignity_Bostrom.pdf.

Brummond, Michael. "Religion in Asimov's Writings.” N.p., n.d., www.angelfire.com/wi/mikebru/Alps.html.

Cooperman, Naomi. "Insufficient Data for a Meaningful Answer: The Use of Language in Isaac Asimov’s “The Last Question”.” Verso, 2011, ojs.library.dal.ca/verso/article/view/527.

Herbrechter, Stefan. "Posthumanism - A Critical Analysis.” N.p., n.d., stefanherbrechter.com/wp-content/uploads/2011/12/Posthumanism-ACritical-Analysis-Preface-and-Introduction.pdf. PDF download.

Papakonstantinou, Yannis. "Created Computed Universe.” Communications of the ACM, June 2015, db.ucsd.edu/wp-content/uploads/2015/07/2015-05-27-p36papakonstantinou-final.pdf. 
Pepperell, Robert. “The Posthuman Manifesto.” Kritikos, February 2005,

dpya.org/en/index.php/File:The_Posthuman_Manifesto_by_Robert

_Pepperell,_Kritikos_V.2_Feb._2005.pdf.

Rangus, Travis. A. “An Overview of "The Last Question”.” N.p., n.d., www.academia.edu/10117805/An_Overview_of_The_Last_Question_.

Shelley, Mary. Frankenstein. Maple Press, 2019.

The Editors of Encyclopaedia Britannica. "Uncertainty Principle.” Britannica, n.d., www.britannica.com/science/uncertainty-principle.

\section{Keerthana Nair \\ ORCiD no.: 0000-0002-7563-4847 \\ BA (Hons.) English \\ Address for communication: \\ Sivadarsanam, 133-B, New Kannimel Nagar, Kilikollur \\ Kollam, Kerala}

The English and Foreign Languages University, Hyderabad

Contact no.: +91 6282724714, E-mail ID: infiniteskeerthana@gmail.com 